\title{
Determination criteria for national water tourism routes
}

\author{
A. Macerinskiene \\ Faculty of Economics, Vilnius University, Lithuania
}

\begin{abstract}
Numerous surface water basins and the natural environment both compound one of the attractive elements that could evolve as an international tourism potential in Lithuania. Active tourism, ecotourism and outdoor tourism are quickly becoming popular and have a great potential to be discovered in Eastern Europe, bearing in mind available water-resources and opportunities. Lithuania takes action in the development of public tourism infrastructure, analysis and evaluation of active tourism fanciers, carries out research on needs and facilities, encourages business initiatives and refines the legal basis, all leading to the promotion of active recreation in the nature and enhancement of tourism opportunities.

A methodology ensuring the evaluation of routes for water tourism suitability was developed with a view to identify particular water tourism routes that would be the most attractive for incomers and domestic tourists and these are known as national routes. The application of criteria, such as the minimal impact of seasonality, climate and meteorology conditions, guarantees the attractiveness of the routes and upholds long-term potential for further development. The methodology has been approved by previously carried out dossier surveys taking interviews from water tourism rent service providers and specifying methodology criteria.

Conformation under methodology has been approved by performing experiential research, i.e. by paddling prospective water tourism routes. Rivers meeting all predetermined criteria within the established methodology have been classified as national water tourism routes in Lithuania. The main tasks on water tourism development with a view to ensure the proper environment for recreation in nature for incomers and domestic tourists are the triggering of basic tourism infrastructure (campsites, respite sites and etc.) and the encouragement of active water tourism marketing.
\end{abstract}


Keywords: active tourism, tourism product, water trail, water route, outdoor tourism.

\section{Introduction}

The economic recession following the financial crisis that begun in 2008 has meant that the majority of the countries have needed to revise their tourism development directions and priorities. This has entailed making corrections to development directions not only regarding incoming tourism, but also regarding domestic tourism [1-4]. It must be noted that certain states in the world (e.g. the U.S.A., Canada, New Zealand and etc.) have always devoted sufficient attention to domestic tourism $[5,6]$.

Foreign authors constantly analyze the benefits of incoming tourism in the context of the full-scale tourism sector [7, 8], stating that domestic tourism development opportunities impacting growth of incoming tourism still have a lot of reserved potential. Old members of the E.U. are familiar with domestic tourism and cherish it as of equal value to incoming tourism [9]. In the meanwhile, the new members of the E.U., e.g. Lithuania, are taking first steps in the discovery of domestic tourism by developing infrastructure and trying to meet the needs of incoming and domestic tourists on an equal basis by searching the potential resources to promote domestic travel.

Usually success of the tourism product is determined not only by the development of services themselves, but also by the development of demand in the market $[10,11]$. Furthermore, every time new opportunities for tourism are evaluated, not only market demand and tourism services created by private initiatives are analyzed, but also the policy of the state devoted to support the development of tourism services that leads to the creation of a tourism product [12] that is attractive to domestic and foreign tourists.

\section{Water tourism service development perspectives}

A complex of coastal nature, internal water basins (over 2850 lakes, 760 rivers) and forests constitute the major potential of nature based tourism resources in Lithuania, taking up to 32 percent of country territory. Especially attractive for the development of ecotourism (cognitive tourism) and active tourism are the protected (preserved) territories (5 national and 30 regional parks, 26 conservation areas, which altogether encompasses 15,3 percent of country territory in total). Natural, rarely urbanized environment, biodiversity and shifting landscape, natural treasures, harmonious culture heritage objects and free travelling opportunities altogether constitute particularities of natural tourism potential in Lithuania and represent a benevolent environment for tourism. Drainage irrigation as an important agriculture processing infrastructure has changed the natural pattern and network of rivers in Lithuania [13].

Ditches amounting to 17,4 thousand $\mathrm{km}$ have been excavated and the watercourse of 46 thousand $\mathrm{km}$ of rivers, rivulets and streamlets have been relegated. At present relegated watercourses constitute $82,6 \%$ and natural genesis 
$17,4 \%$. The total area covered by rivers is $332 \mathrm{~km}^{2}$. The majority of the river network consists of small rivers, rivulets and streamlets up to $3 \mathrm{~km}$ in length, which amounts to 4418 units. There are 816 rivers that are longer than $10 \mathrm{~km}$ and 17 longer than $100 \mathrm{~km} \mathrm{[14].}$

Tourism on lakes and rivers in Lithuania is gaining a great deal of popularity by attracting tourist flows that go for active recreation on water, sightseeing and picnic activities. According to the tasks that are raised in the National tourism development program for the 2010-2013 period, it has been foreseen that it will be necessary to allocate exceptional attention for active tourism products that seek to promote and encourage domestic and incoming tourism.

Back in 2006 water tourism development feasibility studies for Eastern Lithuania and Southern Lithuania were accomplished $[15,16]$ that covered the analysis of past and present water tourism routes. The outcome of the analysis on provided services has revealed that water tourism services within the analyzed regions are underdeveloped. This means that there are no water tourism routes in Lithuania covering active recreation water trails with complementary infrastructure that are accessible at present for navigation while visiting various tourism objects under individual choice. Lately, state owned forest management enterprises on a regular basis establish, refurbish, run and maintain various public tourism infrastructure objects in Lithuania.

Up until 2009 there are 985 recreational objects (campsites, respite sites, footpaths, observation sites and etc.) either established or refurbished and the number is increasing annually. During the period 2002-2006 there were 16 million litas spent by the state owned forest enterprises, furthermore during the 2007-2008 period 7,5 million litas more have been spent for these purposes. In protected (preserved) territories there are 106 cognitive trails, 65 tourism routes, 88 observation sites, 32 information centres providing services for visitors and 400 facilities established and fitted for respite. The biggest nature tourism potential is concentrated in protected (preserved) territories, nevertheless it is not sufficiently used at present because visiting opportunities are limited and recreation activities impeded. It is quite often that unorganized visitors cause harm to the nature, by activities such as littering, erecting campsites in forbidden locations, etc.

The ascending popularity of water tourism is revealed by the rapid development of services in the private sector, i.e. the high number of rent service providers and the diversity of their services. Since 2000 development of rent services for water tourism equipment has been particularly rapid, fig. 1, and particularly those services oriented to the rental services of canoes, kayaks, sculls and support services. Water tourism development was heterogeneous in regional and public infrastructure perspectives and scale. The most rapid growth was experienced by the rental service of canoes, kayaks and scull providers, especially in eastern and southern Lithuania next to the small rivers, i.e. the Aukstaitija and Dzukija regions that are the most attractive tourism regions in Lithuania.

During the last five years water tourism services in Lithuania have developed unpredictably quickly and have been driven by private initiative. Rapid 


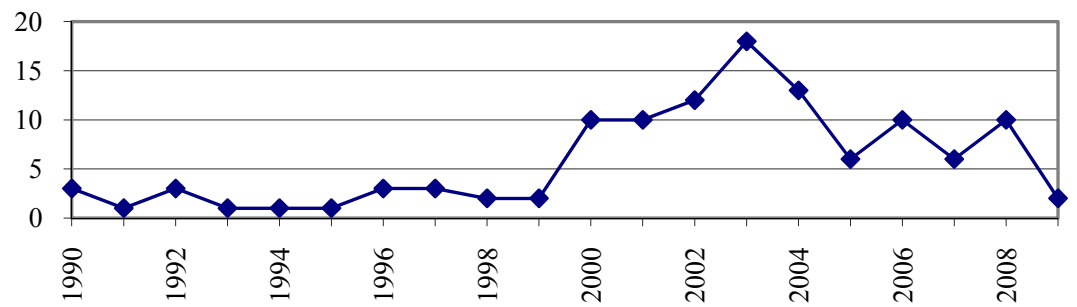

Figure 1: Number of enterprises providing rental services for canoes, kayaks and sculls during the period 1990-2009, \%.

development has led to the actual results of having a large number of canoe, kayak and scull rental service providers in the market, where investments were focused on navigation stock and transportation vehicles for logistic purposes and only a small share was devoted for overnight stays.

In the meanwhile, the activities of protected (preserved) territories administrative bodies and state owned forestry enterprises were focused on the development of public tourism infrastructure.

The negative impact of rapid water tourism development led to the situation where the majority of the rental service providers have targeted the most popular rivers, such as Ula and Merkys, which as a result have become mass tourism locations. Such a situation causes harm to the sensitive environment of biodiversity. In the meanwhile, other rivers that are also potentially attractive for tourism do not become popular only due to the lack of accessible rental services. Triggering of public tourism infrastructure without the establishment of water tourism trails creates recreation opportunities for everyone who wants to tour in nature, but does not promote active, cognitive outdoor tourism in Lithuania.

\section{Main steps in evaluating national water routes}

By ensuring attractive travelling facilities and successful routes along the rivers in Lithuania, it has been foreseen to establish national water tourism routes. National water tourism routes are tourism objects of national importance devoted for tourists and visitors to travel by river, lake or other water basin, which serves as a measure in promoting active tourism and visits to tourism objects.

The identification of national water tourism routes from common Lithuanian water resources network has been accomplished in two stages.

- In the first stage hydrological analysis of Lithuanian rivers has been done by evaluating the potential of national water tourism routes in the present network of water basins.

- In the second stage analysis of water tourism routes has been done by performing expert evaluations (dossier survey, expedition navigations and etc.) in the perspective of tourism. 


\subsection{Main steps in evaluating national water routes}

Within the hydrological analysis of rivers, the following hydrological criteria are determined: debit, ratio of debit and incline, river watercourse incline and the morphometric stretch parameter - sinuosity. While analyzing rivers and dividing them into separate suitable for navigation stretches (segments), it is necessary to find the answers to several questions. This could be done by using the data on hydrological and morphometric parameters:

- is there sufficient quantity of water available in the river and is the river suitable for navigation - these indicators are determined by debit and ratio of debit and incline parameters;

- what is the speed of the river - this indicator is determined by river watercourse incline;

- how difficult is the route due the sinuosity of the river - this indicator is determined by the morphometric stretch parameter sinuosity.

Having done experiential research it has been determined that average annual debit must be above $3 \mathrm{~m}^{3} / \mathrm{s}$; this guaranties that the probability is high enough that it will be possible to navigate in the river in the summer season. The river incline is a longitudinal profile and the water level downfall morphometric rate determines the speed of river flow (current). The river debit and watercourse incline ratio is the parameter $(\mathrm{P})$ that shows the present (or non-existent) opportunity to navigate within the river. After performing experiential navigation it has been determined that fluctuation of parameter $\mathrm{P}$ is determined by the debit rate of the river, which means that we have to evaluate the size of the river watershed with the seasonal fluctuation. If parameter $P$ is under 1,0 it means that it is impossible to navigate in the river, or it is possible to navigate only in spring and the rainy autumn season. Nevertheless, even if the parameter $\mathrm{P}$ rate exceeds 1,0 , we need to evaluate the debit because in the drought season debit might be less than the critical point.

Usually rivers form there watercourses according to interaction laws that occur between the quantity of water, speed (incline) and dirt on which the water is flowing. Rivers with a high incline are not twisty because a strong stream of water surmounts cross circulation; where they erode deep into the ground, valleys are narrow, banks are steep, usually sinuosity is irregular and meander has the form of an elbow that has formed due to an external obstacle. Notionally straight rivers are river stretches that are straight when the sinuosity coefficient is $<1,2$; average twisty when the sinuosity coefficient is $1,2-1,35$; twisty when the sinuosity coefficient is $1,36-1,6$; and very twisty when the sinuosity coefficient is $>1,6$. While paddling in small waterborne tourism transport means in twisty rivers are more captivating, at the same time navigation and accessibility is more adjustable in less twisty rivers. The criteria mentioned above are important not only because the argument of desirability, but also due to the extreme aspects of the river. If the incline of the river and debit is higher than average and the river is very twisty, it becomes very captivating for fanciers of extreme water tourism, such as rafting. However, due to the rarely broken 
landscape territory of Lithuania, there are such rivers only in the spring and autumn inundation period (e.g. Zvelsa, Duksta, Brazuole and etc.); therefore, application of such rivers for tourism is limited.

According to determined dominant hydrological criteria, rivers should be grouped in separate stretches. The length of a particular stretch is a parameter defining duration of the route, which could last for several hours or days.

- $\quad 10-25 \mathrm{~km}$ stretches are one day routes;

- $\quad \sim 50 \mathrm{~km}$ stretches are two day routes;

- $\quad \sim 100 \mathrm{~km}$ stretches are three and more day routes.

While performing hydrological evaluation of the rivers, they are divided into stretches depending on navigation feasibility by setting all year round and seasonal descriptions. Such division of rivers in stretches ensures seamless continuity of national water tourism trails in the constitution of national water tourism routes. River stretches that are feasible for navigation all year round are described in subcategories of big river routes, average river routes and small river routes. River routes that are feasible for navigation only in certain seasons are described in subcategories of extreme high incline routes and less extreme small incline routes.

An additional very important factor in hydrological water tourism analysis is the river outflow hydrological regime characteristic features. In this section of the article the following parameters are analyzed: average rainfall quantity; river supply types (snow, rain and ground); dominant soil ground rocks. These parameters precisely define the quantity of water in the analyzed route in either region during the season, i.e. on the background of these rates it is possible to identify in which stretches of the tourism route the available quantity of water is variable, depending especially on rainfall abundance, and which routes are supplied with ground water.

From a hydrological point of view, one of the most important climate factors is rainfall; this is the only humidity resource making and compensating country water resources, which supplies rivers, ground waters and other water basins. Despite the fact that the Lithuanian territory is notionally small, due to the variety of factors accumulating and redistributing water outflow, the supplying nature of rivers are rather different and have a fundamental impact in determining hydrological regime. River supplying types are as follows: snow, rain and ground water. Typical characteristic feature of Lithuanian rivers are big inundations in spring. In summer and winter rivers abate and periodically experience high waters. Main phases of periodical outflow regime may be very much different in there volumes depending on the environmental conditions of the year.

\subsection{Water tourism route analysis and expert evaluation from a tourism perspective}

Detailed analysis on water tourism resources, services and infrastructure has to be carried out during expedition research and by performing dossier surveys. In the second stage only those routes that have corresponded and have passed 
(according to the description in the section 2.1) hydrological analysis and have been identified as feasible water tourism routes are analyzed further on. This stage of analysis is based on the following criteria:

- evaluation of popularity, when the most popular routs in Lithuania are evaluated;

- analysis of projects related with the water tourism sector that are or have been carried out in municipalities, tourism information centres and regional and national park administrations are analyzed in respect to the routes;

- evaluation of seasonality, by identifying the routes that could be exploited for the longest possible duration during the year.

- $\quad$ picturesque nature and culture objects along the route, thematic variety of available trails;

- $\quad$ expert evaluation on attraction in nature and the cultural perspective.

\subsubsection{Popularity of water tourism}

Water tourism popularity in Lithuania has risen rapidly during the last 5 years. In 2002 water tourism means have been provided by 30 service providers and in 2006 there were already 350; we might forecast that in 2010 the number of rental service providers will not decrease. Merkys river, Ula river, an area of Aukstaitija national park lakes (lith. ANP ezerynas) and the Antaliepte lagoon are the most popular water tourism routes in Lithuania according to the dossier surveys and expert evaluations. Such a situation has been formed on the background of traditional behaviour patterns based on traditions, the natural environment, available infrastructure and mass-media marketing measures, etc.

One of the tourism routes mentioned above is located on the river Ula in Dzukija national park, i.e. in a human activity sensitive environment that has special legislation and tourism impact regulations. Ula water tourism route has an exceptional role in Lithuania: it has a limit of 100 water tourism means and 200 visitors per day. The need to regulate the number of visitors has arisen due to the sensitivity of the natural environment and the high interest of tourists, because Ula is held to be one of the most beautiful, interesting and popular rivers in Lithuania.

This is the only case and other rivers do not have such a high number of tourists yet. Ula river is feeder stream of Merkys river, therefore there is nothing surprising in the fact that it attracts so many tourists. This territory has an intensive market supply of water tourism rental services and a concentrated number of service providers making access to services easy.

The Aukstaitija region has the highest number of lakes in Lithuania (over 1000). Aukstaitija national park is located in the centre of the region; therefore, the central territory of the region receives the highest number of domestic and incoming tourists within the area.

Nature and proper infrastructure attract water tourism service providers and customers. Tourists are usually looking for destinations where they can find various tourism opportunities and a variety of leisure services. In the meanwhile, 
service providers are trying to meet the market needs and provide proper services that would be attractive for visitors.

The Antaliepte lagoon territory is heavily visited by water tourists not only because of the great nature resources, but also because of the successful management activity performed by private service providers: good infrastructure, guaranteed opportunities to get any service needed at any time, explicit guiding on trails, etc. According to the domestic service providers, on average 5 thousand visitors come to the Antaliepte lagoon on weekends. During all the seasons approximately 100-120 thousand tourists visit the area.

Lack of information on water tourism opportunities and sometimes a shortage of basic infrastructure are the limiting factors in other water basins that have a negative impact on tourism development; therefore, it is essential to promote other destinations and facilities. Dissemination of information would discharge the hard flow of tourists that are going for the most popular locations, would assist in solving congestion issues and would have a positive impact on the biodiversity of territories that are overloaded by visitors.

\subsubsection{Input of water tourism projects and other related documentation}

The analysis of 30 studies related with tourism infrastructure next to water resources and water tourism development plans in various regions of Lithuanian was taken from the tourism planning documentation database managed by State department of tourism.

On the basis of the performed analysis of projects directly related with water tourism it is possible to come up with the conclusion that the biggest input and the highest attention is paid to water tourism projects that are related with the following routes: Nemunas river (i.e. the biggest river in Lithuania), the Baltic sea coast (i.e. approximately $100 \mathrm{~km}$ of sandy beach), Curonian lagoon, the lower reaches of Minija river, river Jura and river Dubysa.

The abundance of developed projects indicates that there are many initiatives that combine the natural resources of the rivers with water tourism ideas among the private sector and the state in the perspective of planning.

\subsubsection{Evaluation of seasonality}

A dossier survey must be performed in order to evaluate seasonality by making a comparison of actual water tourism duration with subjective perception of seasonality duration by respondents. At present respondents in Lithuania determine the duration of the water tourism season to be shorter than it actually is. While analyzing water tourism it is mandatory to evaluate not only the temperature, but also the quantity of water in the routes; therefore, priority should be given to the water tourism routes that have a sufficient quantity of water all year round, including drought periods, so that the situation that struck in 2006 (when national routes suffered from drought) will not be repeated. Seasonality could also be shorter due to the winter climate and temperature being below zero, which leads to the closure of the water tourism by making the season shorter. The 2010 indicators are not typical and in our analysis are considered as an exception. 
The analysis of the dossier survey confirmed that water tourism season is much shorter when it could be, i.e. the proper duration of water tourism in Lithuania is 8 (or more) months, fig. 2, under the condition that good water tourism infrastructure and modern waterborne tourism transport means are present, this duration could be exceeded. Lately the duration of 4-5 months has settled upon as the typical duration of the season. According to experts, the water tourism season in Lithuania opens in mid June and closes in mid august, i.e. from Midsummer day (lith. Jonines) until the Equinox (lith. Zolinès).

Nevertheless, service providers open the season in the beginning of June but usually face a small flow of customers. The same situation repeats in August and September before closing for the season. It is important to note that on the contrary in other countries that have a similar climate (i.e. Sweden, the U.S.A., Canada), water tourism is popular in early spring and late autumn.

Neither the first chill nor the spring inundation have any impact on tourists; furthermore, there are trails in Canada that are organized only in autumn when maple leafage turns red, the first frost shows up and hoarfrost covers the ground. In Sweden and Norway, even when the Sun is down, it is normal to have a romantic flotation in the archipelago of islands. Water tourism and water sports in the periods of early and late seasons are considered extreme in Lithuania and are not popular.

\subsubsection{Water tourism magnetism based on nature and culture and the thematic object of trails}

Water tourism resources as a phenomena encompasses more than routes or trails. They include the diversity and picturesqueness of nature and cultural heritage situated along the routes. We also should pay respect to marketing. We should

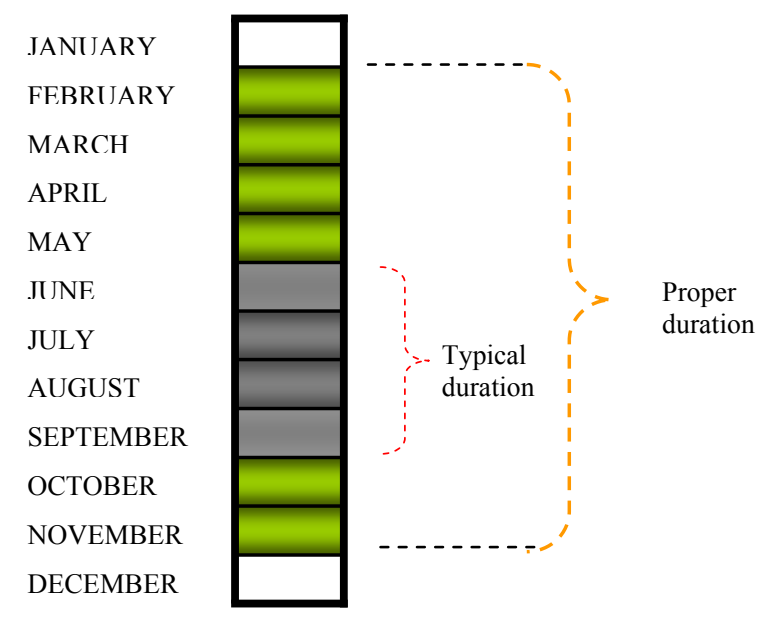

Figure 2: $\quad$ Specific indicators from the hydrological data of water tourism routes are analyzed in the perspective of seasonality. 
not underestimate the importance of public relations, the dissemination of information, explicit guiding on trails, etc.

The dossier survey indicated that sightseeing within various destinations is attractive when tourism objects are less than $1 \mathrm{~km}$ in distance from the route. It has been stated by the respondents that sightseeing tours (bearing in mind that they are performed on foot) are unattractive when they are further than $2 \mathrm{~km}$ from the tour in both directions (from and back to the water), as to visit the object gives a disproportionate balance of physical effort and satisfaction (tourism turns into a hard job).

It was also stated that leaving tourism means and personal belongings on the route without guard is unsafe and the solution of leaving somebody to look after the means and belongings forces tourists to make unsocial solutions and causes annoyance and irritation among the travellers. Therefore, there is a need for infrastructure that would ensure safety and security on the route.

When analyzing marketing measures it must be noted that information conceived for dissemination must contain sightseeing objects located $1 \mathrm{~km}$ in radius on both sides of the river, taking the bank as reference point. Information should cover descriptions of the objects and information tour duration from and back to the water. At present the majority of tourism objects are hard to access, especially from the river side, and many of them are unfit for tourism needs. We could forecast that the more public infrastructure is developed the greater the interest in sightseeing objects from tourists. When setting priorities for shortlisting culture and natural objects that should be accommodated to tourism needs, it would first be wise to prepare objects for tourism that are located next to the national water tourism routes.

One more important criterion when identifying national water tourism routes is issues related with thematic trails. When trails have (1) historical confirmed records of national importance, (2) the opportunity to choose from a variety of waterborne tourism transport means (raft, canoe, scull, inflatable, motorboat and etc.), (3) a water route with plenty of shoals, (4) access to mythology objects (adder stones, bowls and etc.), this make the route important and puts it in a higher position on the national importance route list. During experimental research and harmonization debates at the stage when decisions must be concretized, it is planned to put the routes encompassing strong records of thematic trails on a shortlist, ensuring that the network of national water tourism routes will be picturesque in terms of nature and culturally solid in terms of heritage.

\subsubsection{Expert evaluation of routes}

At the final stage of evaluation, the previously determined shortlist of national routes, before being confirmed as the final list, is subject to expert evaluation via experiential research, i.e. taking a boat and navigating down the routes.

Analysis of water tourism routes, accomplished both during the hydrological and expert evaluation stages, ensures that the identified routes have a high potential and helps in the development of promotion ideas. It also allows one to notice mistakes and oversights in the evaluation process that have been done 
during the previously performed stages and allows one to make corrections and amendments.

In the case of Lithuania, expert evaluation revealed that in addition to already identified routes that meet the criteria described above, there must be several amendments made by including routes that are latched on to by tourists and have a naturally sculpted popularity (Lakaja river, Ula river and lake areas of Veisiejai regional park and Aukstaitija national park).

\section{Network of national water tourism routes and its establishment values}

After all evaluation stages are finished it is planned to map national water tourism routes on the following water basins: (1) Nemunas river tourism route, (2) Merkys river and Ula river tourism route, (3) Neris river tourism route, (4) Zeimena and Aukstaitija national park lakes are tourism route, (5) Sventoji river tourism route, (6) Dubysa river tourism route, (7) Jura river tourism route, (8) Minija river tourism route.

A substantial scheme for shaping national routes is based on the national water route concept guidelines, because they precisely correspond to national water route establishment values and tourist needs and potential. The national water route establishment values are described below.

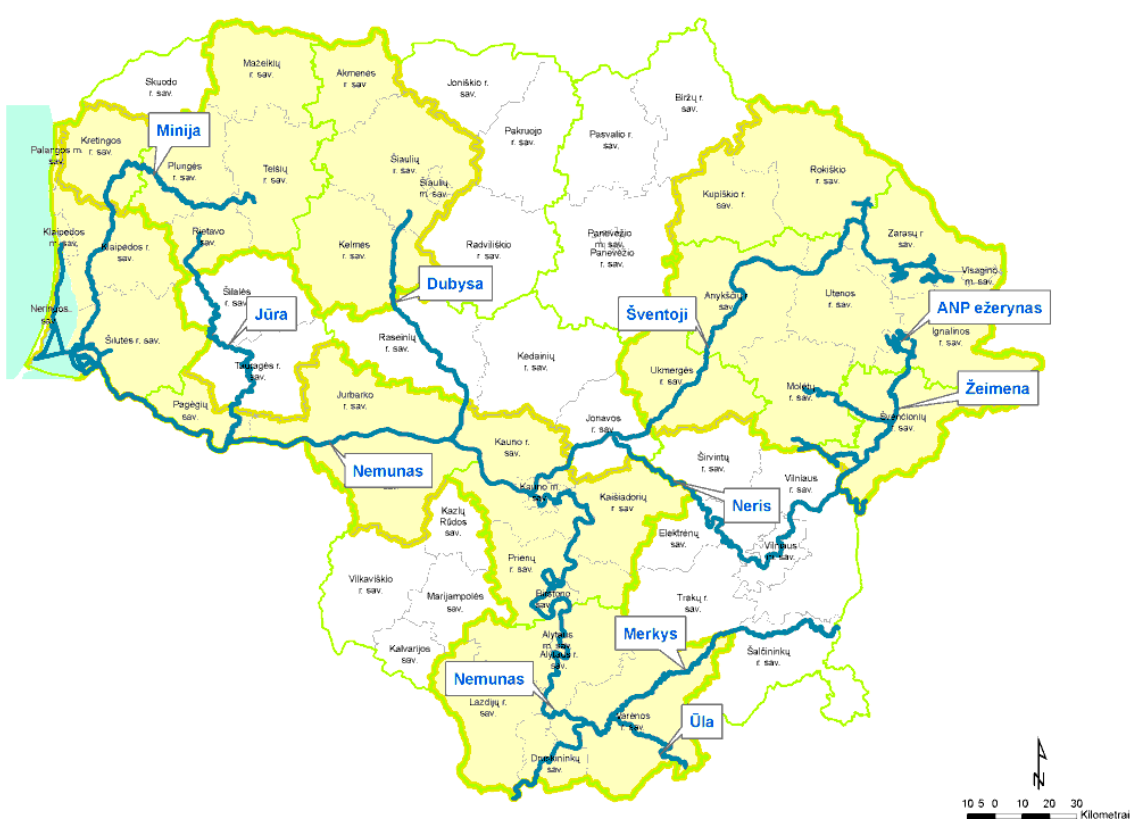

Figure 3: Network of national water tourism routes. 
Safety. Trips done by waterborne tourism transport means must be safe in many aspects, for example from a naval safety point of view in internal water roads and from an infrastructure point of view in the actual location, where tourists must be provided with full information on water obstacles and available embarkation facilities.

Universality. While creating a common water tourism system, national water tourism routes are determined in the way that international, national and domestically planned tourism routes would combine together into the solid network in such a way as to create opportunities to prolong trip duration, including sightseeing objects, into the common national tourism system. National routes are the ones that have the longest duration of the water tourism season; therefore, integration of Lithuania's smaller rivers into the common national water tourism route system is accessible in a proper and adequate manner based on actual feasibility. The universality of routes is closely related with issues of thematic content when holidaymakers and tourists may choose not only to navigate on surface waters and reach one or another destination, but also to familiarize themselves with the theme of the route (mythology, history based trails, trip on rafts and etc.).

Tourism magnetism (attractiveness). National water tourism routes are mapped on the main Lithuanian rivers, lake areas and three national parks of Aukstaitija, Dzukija and Curonian Neringa by emphasizing the value of nature to promote opportunities to visit destinations by water. The benefits of active tourism are also emphasized in a daily life context. An important issue is the fact that mapping of behaviour patterns is established on a bank sheet without having to face a spontaneously evolved flow of tourists. It is necessary to inform tourists and dispense their flow sustainably within Lithuania, based on individual needs and potential. This would lead to the discovery of new resources and services in the future.

Development perspectives. National water tourism routes are established in locations where the water has been running for centuries and has been used for human needs in one or another way. At present, active tourism has become popular and therefore its importance in daily life must also warrant more attention. Water tourism routes designed at present will connect water basins into the common system by creating infrastructure next to the routes all over the Lithuanian territory. Such a principle of creating a water tourism system is based on the fact that all small rivers belong to the watersheds of bigger ones; therefore, the opportunity to integrate domestic routes that meet other criteria of attractiveness (e.g. level of extreme and etc.) into the system opens up an opportunity to have a sustainably developed network of water tourism in Lithuania.

Rationality. The system of national water tourism routes is related with the internal water roads, stationary piers and mobile landing-stages and the most popular at present are the water tourism routes and trails. It is important to note that these facility solutions are fully harmonized with territory management plans supervised by the State service for protected areas under the Ministry of Environment. It helps to avoid conflicts in the protected (preserved) territories by 
addressing and meeting requirements set in legislation that applies solutions, planning, designing, implementation and supervision of this level and type of environment intervention.

\section{Conclusions}

1. There are two main stages in the evaluation of water tourism route feasibility for tourism: hydrological and expert evaluation. When identifying routes for tourism needs hydrological criteria are analyzed first because they determine the status of routes in the tourism system, i.e. river debit, ratio of debit and incline, sinuosity, factors impacting seasonality (e.g. climate). Expert evaluation is accomplished by taking two measures: dossier survey and expeditions. This part of analysis is based on evaluation of the following factors: popularity; implemented projects that are related with water tourism; seasonality; resources of culture and nature (including magnetism); experiential verification of picturesque nature and culture relish performed by experts.

2. The national water tourism route system encompasses eight routes: Nemunas river tourism route, Merkys river and Ula river tourism route, Neris river tourism route, Zeimena and Austaitija national park lakes are tourism route, Sventoji river tourism route, Dubysa river tourism route, Jura river tourism route, Minija river tourism route. All proposed routes establish a consistent network of water tourism routes covering all regions of Lithuania by creating opportunities for active tourism attracting not only domestic, but also international tourists. A network of routes encourages business initiatives and public investments into the infrastructure.

3. Water tourism magnetism is created by the route itself and by the nearby existing tourism terrain with sightseeing objects located $1 \mathrm{~km}$ in radius on both sides of the river, taking the bank as reference point. An essential role is played by interesting sightseeing objects that accommodate tourists, basic infrastructure (stationary piers and mobile landing-stages and etc.), facilities enhancing halt and stopping available every $5 \mathrm{~km}$ of any route (campsites, respite sites, observation sites and etc.), labelling/marking infrastructure within the terrain, ensuring explicit guidance on routes and trails (stands, signs, landmarks and etc.), dissemination and accessibility to information (pamphlets, leaflets, maps and etc.).

\section{References}

[1] East Dunbartonshire Tourism Strategy \& Action Plan 2008 - 2011. 2007, p. 17

[2] East Ayrshire Tourism Strategy \& Action Plan. The Way Ahead 20092015, 2009 p.38

[3] Experience Perthshire Tourism Strategy \& Action Plan 2006 - 2011, 2006, p. 46 
[4] German Federal Government Policy Guidelines on Tourism. General Economic Policy/Industrial Policy, Federal Ministry of Economics and Technology, 2009 p.14

[5] Building a National Tourism Strategy. A framework for Federal/Provincial/Territorial Collaboration 2007, p.20

[6] Southland Tourism Strategy 2005 - 2015. 2005, p.65

[7] Chang H. H., Lai T. The Taipei MRT (mass rapid transit) Tourism Attraction Analysis from the Inbound Tourists' Perspectives. Journal of Travel \& Tourism Marketing; Jul-Sep2009, Vol. 26 Issue 5/6, p445-461, $17 \mathrm{p}$.

[8] Sahli, Mondher, Nowak, Jean-Jacques. Does Inbound Tourism Benefit Developing Countries? A Trade Theoretic Approach. Journal of Travel Research; May2007, Vol. 45 Issue 4, p 426-434, 9 p.

[9] Torkildsen G. The Environment, countryside and open space (Chapter 15). Leisure and Recreation Management. Routledge: London, pp. 303-323, 2005.

[10] Holloway J. C., Taylor N. The demand for tourism (Chapter 4). The business of Tourism, 7th ed, Pearson Education Limited: London, pp. 6490, 2006.

[11] Page S. J. The Supply of Tourism (Chapter 4). Tourism Management. Managing for Change, 3rd ed., Oxford: Butterworth-Heinemann, pp. 119152, 2009.

[12] Garcia, G.M., Pollard, J., Rodriguez, R.D. "The planning and practice of coastal zone management in Southern Spain", Journal of Sustainable Tourism, Vol. 11 No.2/3, pp.204-23, 2003.

[13] Turner, Barnard. Economic, Social, and Cultural Contexts for Market and Product Diversification of the Lithuanian Tourism Sector. Transition Studies Review, 2007, v. 14, is. 3, pp. 525-42

[14] Gailiusis B., Jablonskis J., Kovalenkoviene M. Rivers in Lithuania: hydrography and outflow. - Kaunas, 2001.

[15] Macerinskiene A. Feasibility Study for Water Tourism Development in East of Lithuania, Vilnius, 2006, p. 123.

[16] Macerinskiene A. Feasibility Study for Water Tourism in South of Lithuania, Vilnius, 2006, p. 145. 